\title{
De rol van de treasury afdeling in het economisch risicobeheersingsproces
}

Drs. M. M. Wielinga

\section{$1 \quad$ Inleiding}

Voor het management van het economisch risico, gedefinieerd als de invloed van onverwachte wisselkoersschommelingen op toe komstige kasstromen van een onderneming, staan verschillende marketing- en produktiestrategieën ter beschikking. Het investeren in flexibiliteit van de produktie of een andere inkooppolitiek - met inachtname van een behoorlijke logistieke coördinatie - verschaft in sommige gevallen de mogelijkheid wisselkoersveranderingen te gebruiken voor het ontwikkelen van een concurrentievoordeel. Ondernemingen die wel in staat zijn hun operaties flexibeler in te richten maar dit nalaten, verkleinen hun overlevingskansen. In de literatuur wordt opgemerkt dat de treasurer bij het management van het economisch exposure een belangrijke rol speelt. Aan de hand van een economisch exposure raamwerk zal hij beleidsaanwijzingen geven die de inkoop-en produktieafdelingen kunnen gebruiken bij het zoeken naar nieuwe leveranciers en/of produktielocaties. Het management van het economisch exposure loopt door de gehele onderneming heen; het is logisch dat van een geïsoleerde positie van de treasury afdeling geen sprake kan zijn.

Uit een door de auteur uitgevoerd onderzoek onder achttien treasury afdelingen komt een ander beeld naar voren. De treasury staat volgens de geinterviewde treasurers 'los van de bedrijfsactiviteiten' en enigszins 'geïsoleerd van de rest van de onderneming'. De werk- zaamheden van de treasurer beperken zich tot het afdekken van transactie- en renterisico's. Van een zogeheten service-georiënteerde afdeling is geen sprake en het management van het economisch exposure krijgt op het niveau van de concern treasury nauwelijks aandacht, hoewel velen erkennen dat dit risico dominant aanwezig is.

In het onderzoeksrapport worden de determinanten en het management van het economisch risico eerst in theorie behandeld, gevolgd door de resultaten van een empirisch onderzoek. In dit artikel behandelen wij uitsluitend enkele van de empirische resultaten.

\section{Instrumenten van het economisch risico}

Er bestaan diverse produktie- en marketingstrategieën met betrekking tot de beheersing van het economisch risico. In de praktijk wordt vaak gehoord dat de financiële technieken voor het afdekken van het economisch exposure niet voldoen. Het is daarom verrassend te noemen dat twee van de twintig ondernemingen expliciet aangeven dat zij het economisch risico afdekken met behulp van finan-

Drs. M.M. Wielinga heeft in de periode november 1992 - mei 1993 een afstudeeropdracht uitgevoerd bij Van Den Boom Groep, onder begeleiding van Dr. J. de Haan en Drs. R.C. Coppes, docenten aan de Economische Faculteit van de Rijksuniversiteit Groningen. Het empirische deel van het stagerapport over de rol van de treasury afdeling in het beheersingsproces van economische valutarisico's, werd voor deze uitgave bewerkt. Momenteel werkt de auteur bij ABN AMRO-corporate finance. 
ciële instrumenten. Eén treasurer merkte in dit verband het volgende op:

'Wij hebben een groot economisch risico in Land A, want daar zitten veel van onze concurrenten, dus de lokale prijzen zijn niet aanpasbaar. Bij een devaluatie van de munteenheid van het betreffende land komt onze gehele winst onder druk te staan. Daarom is het noodzakelijk dat de treasury, wanneer een devaluatie van een bepaalde munt wordt verwacht - zoals afgelopen september (1992 - M. Wielinga) - de geschatte omzet afdekt. Dat kan voor 6, 12 of 18 maanden. Eventuee/ wat langer. Gezien onze zeer constante export naar dit land zijn we goed in staat ons economisch exposure naar dit land te berekenen. (...) Daarbij merk ik op dat van opsplitsing en verplaatsing van onze produktie geen sprake kan zijn, want die moet grootschalig plaatsvinden.'

De andere treasurer stelde:

'Economisch risico, daar kun je weinig mee. Het enige dat je kunt doen is je dollarposities goed proberen in te schatten en gebruik te maken van financiële instrumenten. Anders moet je andere markten betreden, kosten reduceren of je kostenstructuur aanpassen. Maar dit is moeilijk. In onze sector moet je je met alle activiteiten bezighouden, wil de onderneming een 'mayor player' zijn en dat is ons streven. Het is een strategisch 'issue'. Er moet wel een echt debãcle zijn wil de ondernemingsleiding tot het besluit overgaan dat we onze diensten ergens ter wereld niet meer aanbieden. (...) De markt dicteert waar je moet zitten en hoe er wordt afgerekend.'

Onze verwachting is dat meer treasury afdelingen zich met dergelijke activiteiten inlaten. De rekbaarheid van de opmerking 'afdekken tegen de onderliggende bedrijfsstroom' geeft daar aanleiding toe. Wat is immers de planningshorizon van de 'onderliggende bedriffsactiviteiten'?

Daarmee willen wij niet suggereren dat treasurers ongelimiteerd speculeren of anderszins zich schuldig maken aan ongeoorloofd gedrag. Het volgende voorval illustreert dit. In de periode dat de interviews werden afgenomen werd een groot financieel schandaal bekendgemaakt bij Shell Japan. Treasurers aldaar hadden te veel gespeculeerd op een stijgende Dollar. In vier van de zeven interviews die nadien nog werden afgenomen werd er geheel op eigen initiatief van de betreffende treasurer - op de noodzaak van een goed 'performance measurement'- en management informatiesystemen gewezen, terwijl dit onderwerp in voorgaande interviews niet één keer ter sprake was gekomen.

Ook andere studies wijzen erop dat in de praktijk gebruik wordt gemaakt van financiële instrumenten voor de afdekking van het economisch risico. Een studie onder Engelse treasurers van multinationals door Belk en Glaum wijst uit dat financiële instrumenten zelfs de belangrijkste plaats in het economisch risico management innemen.

'All of the above nine companies (van de achttien door Belk en Glaum onderzochte ondernemingen, $M$. Wielinga) had the management of their expected future cash flows closely interlinked with the management of actual transaction exposures. (...) Only three companies responded that exchange rate considerations played a role at all in non-financial decision making areas (e.g. sourcing, product development or production location), but even with these companies the role was only minor.' (1990, p.7)

Wij krijgen het idee dat in de onderzochte ondernemingen niet zo sterk op financiële instrumenten geleund wordt als in de Engelse multinationals. Een andere Nederlandse studie komt tot soortgelijke resultaten. Uit een analyse van 15 achtereenvolgende jaarverslagen van veertien Nederlandse multinationals blijkt dat slechts één onderneming zich met behulp van financiële instrumenten afdekt voor het economisch risico (De Jong en Ligterink, 1992b, p.16). Het afdekken van het economisch risico met behulp van financiële instrumenten is een potentieel gevaarlijke strategie en nader onderzoek lijkt op zijn plaats. 
De verantwoordelijkheid voor het management van het economisch exposure ligt niet, zoals al eerder in dit verslag opgemerkt, bij de concern-treasurer. De verantwoordelijkheid ligt in de meeste gevallen bij de ondernemingsleiding of bij de werkmaatschappijen. Toch is het interessant een inventarisatie te geven van de instrumenten die in enkele gesprekken genoemd zijn. Met nadruk stellen we dat het hier niet gaat om een uitputtende opsomming.

\section{Marktmacht en prijszettingsgedrag}

Tien treasurers gaven aan, dat hun onderneming in bepaalde activiteiten zo machtig zijn dat wisselkoersfluctuaties kunnen worden doorberekend in de prijzen. Eén treasurer vatte dit als volgt samen:

(...) een groot gedeelte van de wisselkoersfluctuaties wentelen we gewoon af op de consument.'

In een tweede onderneming maakt het afwentelen van wisselkoersschommelingen op afnemers zelfs een onderdeel uit van de concernfilosofie:

'Elk van onze werkmaatschappijen moet bij de top drie van de wereld behoren. Behoort een werkmaatschappij niet tot de 'Top Drie', en is hij ook niet in staat binnen afzienbare tijd een dergelijke positie te verwerven, dan stoten wij deze werkmaatschappij af.'

Of een onderneming wisselkoersschommelingen in de prijzen kan doorberekenen, hangt zoals gezegd af van de gevoeligheid van de vraag voor veranderingen in de prijs. De volgende opmerking illustreert dit probleem zeer aardig:

'Je moet een goed onderscheid maken tussen de verschillende markten waarop wij als onderneming opereren. De ene markt wordt gekenmerkt door een hoge toegevoegde waarde van het aangeboden produkt en een bescheiden concurrentie. Onze onderneming is hier een belangrijke aanbieder, wij zijn prijszetter. De andere markt wordt gekenmerkt door een stevige concurrentie, hier zijn we duidelijk een prijsvolger. Voor een dergelijke markt moet je ook andere strategieën ontwikkelen. Zo hebben wij in de periode dat de Dollar laag stond een stevig service- en distributiekanaal in de Verenigde Staten opgezet om onze klanten aan ons te binden.'

In één geval bestaat er een duidelijk streven naar de vergroting van de marktmacht: ' $/ \mathrm{k}$ heb al aangegeven dat de enige mogelijkheid die wij zien voor de beheersing van het economisch risico financiële afdekking is. Natuurlijk kun je ook proberen een vuist te maken in het land waar je naar exporteert. Daarin schuilt natuurlijk de bestaansgrond van de voorgenomen overname.'

\section{Andere marketingstrategieën}

Marktselectie en het verplaatsen van de verkoop, is geen populaire strategie onder de ondervraagde treasurers. Zes treasurers gaven aan dat een dergelijke strategie nadelige consequenties voor de concurrentiepositie heeft, 'want als de concurrent een markt betreedt dan moeten wij wel volgen'. Toch zijn niet alle treasurers even blij met de expansiedrift van de marketingafdeling:

'Een echte belangentegenstelling met de marketing-afdeling heeft zich tot op heden niet voorgedaan. Wel hebben wij af en toe problemen met de verkoop in niet-transferabele valuta's. Dan zeggen we: 'Jongens, grandioos zo'n nieuw verkoopkantoor daar in Afrika, maar aan schelpen hebben we niets.' (...) Je moet de mensen van 'sales' omturnen: 'Verkoop met credit cards!', 'Verkoop in andere, harde, valuta's!'.'

Een treasurer van een andere zeer grote onderneming schetste een beeld waaruit blijkt dat soms een gezonde kosten/baten-analyse door de marketing-afdeling achterwege blijft: 'Een dergelijk probleem deed zich voor toen we naar China gingen. De ondernemingsleiding vond het uit strategisch oogpunt van be- 
lang om de Russische markt op te gaan en deze te penetreren. En dat terwijl de Li een niet-transferabele munteenheid is. Ach, daar zijn natuurlijk oplossingen voor. Er wordt op dat punt veel samengewerkt door Nederlandse bedrijven. Maar ten aanzien van het te voeren marketingbeleid in Rusland hebben we de corporate finance officer van de betreffende business unit duidelijk gemaakt dat verkoop in Roebels zinloos was, dat is onnodig risico's nemen. Uiteindelijk is gekozen voor verkoop in Dollars.

Indien er zich een belangentegenstelling voordoet dan komen we meestal in onderling overleg tot een werkbare oplossing. De Ruslandstrategie heeft echter op top-niveau gespeeld.

\section{Produktiestrategieën}

Een eerste genoemde produktiestrategie is de timing van acquisities. Een treasurer vertelde dat de beslissing om halverwege de jaren tachtig in de Verenigde Staten een grote overname te doen mede werd ingegeven door de ondergewaardeerde Dollar. Een ander merkte op dat de beslissing om een goed distributienetwerk in de Verenigde Staten op te zetten ook werd ingegeven door de lage Dollar. Het bedrijf was hierdoor beter in staat zijn produkten te blijven afzetten toen de Dollar weer eenmaal begon te stijgen. De rol van de treasurers bij dergelijke operaties is beperkt. Drie treasurers gaven aan dat zij, in het geval de ondernemingsleiding besluit ergens te gaan investeren of een buitenlands bedrijf over te nemen, de treasury, daar - zijdelings - bij betrokken werd. De beleidsvoorbereiding werd meestal gedaan door de afdeling 'Strategische Planning'. Op de suggestie onzerzijds dat de onderneming wellicht in staat zou zijn gedeelten van de produktie te verplaatsen werd er herhaaldelijk geprotesteerd. Acht treasurers waren het hier niet mee eens. Meest genoemde bezwaren zijn de arbeidsmoraal van een land (twee maal), hoge initiële investeringen en 'sunk costs' (vijf maal), fiscaal regime (twee maal) en te kleine series (drie maal).
'Bij het verplaatsen van de produktie zijn zoveel zaken die meespelen, zoals arbeidsethos, fiscale zaken, en ach ja, ook weleens valutaschommelingen. Trouwens, vanuit een logistiek oogpunt kan verplaatsing bijzonder vervelend ziin.'

'Weet u wat zo'n 'plant' kost? Die verplaats je niet zomaar. En een tweede erbij bouwen in een ander land heeft weinig zin, daarvoor zijn onze series te klein.'

De algemene opinie is dat investeringsbeslissingen zeer gecompliceerd in elkaar zitten en dat valutaire overwegingen daar een bescheiden rol in spelen. Het versneld in gebruik nemen van een gedeelte van de produktiecapaciteit, of het versneld afstoten is wel een reële optie. De investeringsbeslissing is dan reeds genomen.

Wij bezitten enkele tientallen produktie-eenheden over de gehele wereld. Met die produktiecapaciteit kunnen we wel wat schuiven, dat dicteert de markt ook wel. Nieuwe capaciteit opbouwen, dat is geen optie. Wel kunnen investeringen opgetrokken worden, zoals we nu doen met onze italiaanse werkmaatschappij. Deze werkmaatschappij produceert nu nog uitsluitend voor de lokale markt, bij voltooiing van nieuwe produktiecapaciteit (die een jaar eerder dan oorspronkelijk gepland in gebruik zal worden genomen) zullen we ook voor de export produceren.'

Een vaker aangehaald bezwaar tegen het schuiven met produktiecapaciteit en voornamelijk de inkoopstromen is de moeilijke logistieke coördinatie van dergelijke operaties. Wij moeten ons dus goed realiseren dat investeren in flexibiliteit van de operaties niet afdoende is om op adequate wijze te reageren op wisselkoersonevenwichtigheden.' Investeringen in het logistieke apparaat zijn onontbeerlijk. In figuur 1 worden de genoemde strategieën vermeld. Zoals uit het figuur blijkt komt de studie van De Jong en Ligterink (1992b) tot vergelijkbare uitkomsten. ${ }^{1}$ 
Figuur 1 Produktie- en marketingstrategieën.

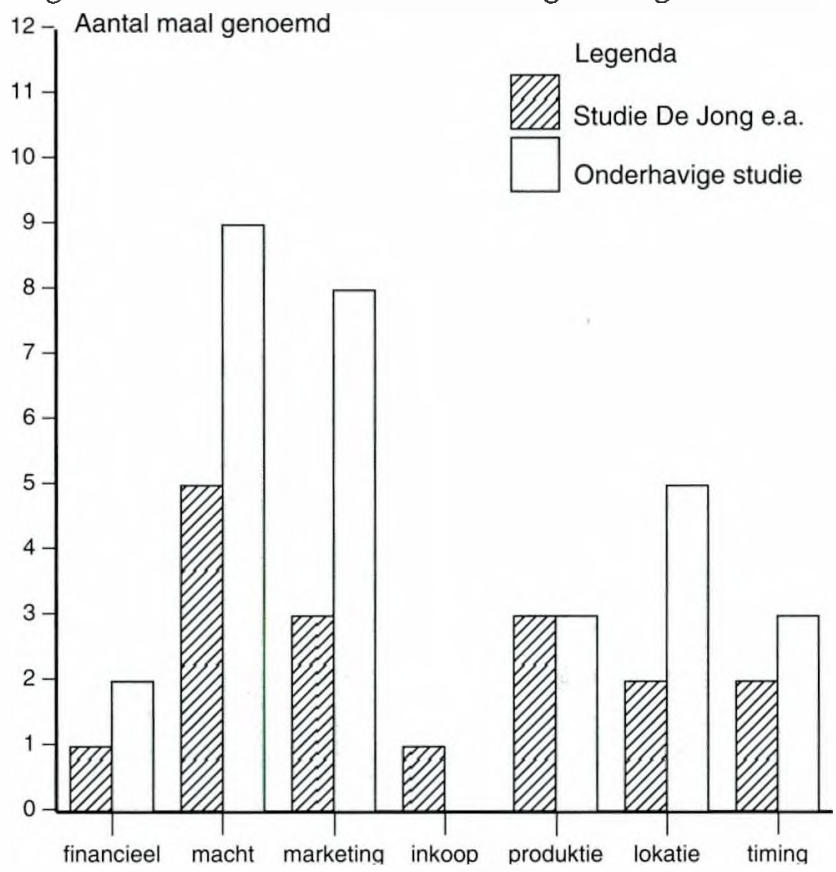

In geen enkele onderneming hebben wij een raamwerk voor een effectief economisch exposure management gevonden, gericht op het vergroten van de flexibiliteit van de produktieafdeling en het inkoopapparaat. Hoewel één treasurer laat doorschemeren dat hij hier in de toekomst meer aan wil gaan doen, eventueel in samenwerking met de afdeling Planning. Twee andere treasurers zeggen dat zij het idee hebben dat er binnen hun werkmaatschappijen wel gewerkt wordt aan het vergroten van de flexibiliteit van de inkoop. Dit proces wordt echter niet gecoördineerd vanuit de centrale treasury. Wij moeten ons overigens bedenken dat het niet vreemd is dat we een dergelijk raamwerk niet hebben gevonden. De interviews zijn in de meeste gevallen gehouden met concerntreasurers. In de meeste gevallen zijn zij niet verantwoordelijk voor het management van het economisch risico. In vervolgonderzoek zal meer nadruk moeten worden gelegd op de beheersing van het economisch risico op werkmaatschappij-niveau.

In zeven gevallen speelt de concerntreasury een adviserende rol met betrekking tot de beheersing van het economisch risico.
De invulling van die adviserende rol was divers: - in samenwerking met de controller de 'inflexibiliteitsperiode' van een produkt bepaIen;

- advies geven over gevolgen van een devaluatie/revaluatie van één van de kernvaluta's van de onderneming;

- advies geven over opbouw van de kostenstructuur van de onderneming.

Vier treasurers gaven toe dat er meer op dit gebied kan gebeuren. Maar in het geven van een interne cursus werd weinig gezien. Daarvoor is de materie te complex. Eerder zal moeten worden gewerkt aan een overlegstructuur tussen de verschillende afdelingen, gecoördineerd door de directeur Financiële Zaken. Duidelijk is dat de aandacht voor lange-termijnwisselkoersonevenwichtigheden binnen ondernemingen groeit. Het lijkt niet meer dan logisch dat de treasurer - met al zijn expertise - zich meer dan tot op heden het geval is, gaat toeleggen op deze fascinerende materie, vooral bij ondernemingen die in staat zijn een meer flexibel produktieapparaat op te bouwen, of inkoopstromen te verleggen.

\section{Tot slot}

De theorie van het economisch risico en de beheersing ervan is een veelomvattend terrein. Beter begrip van de invloed van wisselkoersschommelingen op de concurrentiepositie van de onderneming zal de ondernemingsleiding in staat stellen een comparatief voordeel te behalen. Verder onderzoek hiernaar is een belangrijke uitdaging.

\section{Literatuur}

Akerlof, G.A. (1970), The market for Lemons: Quality Uncertainty and the market mechanism, Quarterly Journal of Economics, nr. 84, pp. 488-500.

Austen, M.E. \& P.J. Reyniers (1986), International Treasury Management Handbook, Euromoney (Londen).

Bakker, M. (1991), Financiële kopstukken willen meer erkenning, FEM, pp. 92-94 
Begg, D. (1989). Floating exchange rates in theory and practice, The Oxford Review of Economic Policy, vol. 5 , nr. 3, pp. 24-89

Belk, P.A. \& M. Glaum (1990), The management of foreign risk in UK multinationals: An empirical investigation, Accounting and Business Research, Vol. 21, no. 81, pp. 3-13.

Bergsma, S. \& A.R.G.J. Zwiers (1990), Internationale financiering bij Akzo. In: Jager, H: \& E. de Jong (red.) (1990), Internationale financiering, de theorie en de Nederlandse praktijk. Stenfert Kroese (Leiden).

Boom, L.P.E.M. van den (1992), De toegevoegde waarde van treasury management, deel 1: Karakteristiek van de treasury functie, Maandblad voor Bedriffsadministratie en Bedrijfsorganisatie, jaargang 96. nr. 1141, pp. 78-82

Capel, J.J. (1991), Principles for profitable economic exposure management, paper prepared for the Competitive Paper Session of the $17^{\text {th }}$ Annual Conference of the European International Business Association, December 1991

Capel, J.J. (1993). Exchange rates and strategic decicions of firms (dissertatie). Tinbergen institute research series, subseries General Economics, nr. 47.

Croese, D. (1990), Valutarisico bij buitenlandse aannemingswerken. In: Jager, H. \& E de Jong (red.) (1990), Internationale financiering, de theorie en de Nederlandse praktijk. Stentert Kroese (Leiden)

Croese, D., A.B. Dorsman \& A. Klaassen (red.) (1985), De organisatie van het vreemde-valutabeheer. FINEMrapport, Kluwer.

Damme, E.E.C. (1990), Speltheorie, ESB, 75e jaargang $\mathrm{nr}$. 3782, pp. 1036-1042.

Daniels, J.D. \& L.H. Radebaugh, (1989), International Business, Addison-Wesley Publishing Company (New York).

Dixit, A. (1989), Entry and Exit Decisıons under Uncertainty, Journal of Political Economy, vol. 97. nr. 3, pp. 620-638

Dufey, G. \& S.L. Srinivasulu (1983), The case for corporate management of foreign exchange risks, Financial Management. Winter 1983, pp. 54-62.

Earl, M.J. (1985), Stadia in het beheer van valutarisico's. Tijdschrift Financieel Management, pp. 38-45

Eiteman, D.K. \& A.I. Stonehil (1992), Multinational Business Finance, Addison Wesley, Reading Mass.

Flood, E.Jr. \& D.R. Lessard (1986), On the measurement of operating exposure to exchange rates: A conceptual approach, Financial management, Spring 1986, pp. 25-36.

Jong. E. de \& J.E. Lıgterınk (1992a), Valutaire invloeden op veertien Nederlandse bedrijven, Tijdschrift voor bedrijfsadministratie, jaargang 96, nr. 1147

Jong. E. de \& J.E. Ligterink (1992b), Foreign exchange exposure of the most important non-financial Dutch companies, size and strategic responses, Universiteit van Amsterdam, Department of economics, research memorandum nr. 9225.

Kemna, A.G.Z. (1989), Reële opties in investeringsprojec ten, MAB, september 1989, pp. 355-364.

Koster, L.J. \& M. Gruiters, (1993), Van translatierisico naar transactieresultaat, Tijdschrift Financieel Management, nr. 2, pp. 8-14

Krijnen, H.G. (1986), Strategie en Management, Wolters Noordhof (Groningen).
Krugman. P. (1989), The case for Stabilizing Exchange Rates, The Oxford Review of Economic Policy, vol. 5. nr. 3, pp. 61-72.

Kuik, J. (1990), Organisatorische aspecten van de treasury, in Jager. H. \& E. de Jong (red.) (1990), Internationale financiering. de theorie en de Nederlandse praktijk. Stenfert Kroese (Leiden).

Lanjouw, G.J. \& M.M. Wielinga (1994), De politieke economie voor protectie en anti-protectie, Maandschrift Economie, jrg. 58, april 1994, pp. 113-128

Lessard, D.R. \& J.B. Lightstone (1986), Volatile exchange rates can put operations at risk. Harvard Business Review, July/August 1986, pp. 107-114

Levi. M.D. (1983), International Finance - Financial management and the international economy. McGraw-Hill (New York).

Luehrman, T.A. (1990), The exchange rate exposure of a global competitor, Journal of International Business Studies, Vol. 21, pp. 225-240.

Oxelheim, L \& C.G. Wihlborg (1987). Macroeconomic uncertainty - International risks and opportunities for the corporation. John Wiley and Sons (Chicester)

Porter, M (1980), Competitive Strategy, The Free Press (New York)

Rappaport, A. (1986), Creating Shareholder Value: The new standard for business performance. The Free Press (New York)

Reeders, A. (1987). Definition and design of the treasury function in Dutch business, End-of-study assignment for the MBA-program 1986/87. Nijenrode, The Netherlands School of Business.

Robertson. T.S. \& A.C. Shapiro (1976), Managing foreign exchange risks: The role of marketing strategy, Working Paper, University of Pennsylvania

Shapiro, A.C. (1992), Multinational Financial Management, Allyn and Bacon (Boston)

Stiglitz, J.E. (1988), Economics of the Public Sector, W.W Norton \& Company (New York).

Snijders, D. (1990), Global Company and the World Financial Markets in Sijben, J.J. Financing the World Economy in the Nineties, Kluwer Academic Publishers (Dordrecht).

Soenen, L.A. \& R. Aggerwal (1989), Cash and foreign exchange management: theory and corporate practice in three countries, Journal of Business Finance and Accounting, Vol 16, no. 5, pp. 599-619

Volberda, H. (1992), Organization Flexibulity: Change and Preservation - A flexibility Audit and Redesign Method (dissertatie), Wolters Noordhoff (Groningen)

\section{Noot}

1 In de studie van De Jong en Lıgterink (1992b) wordt ook vermeld welke ondernemingen welke strategie hebben gebruikt. Om enig misverstand te voorkomen vermelden wij hier alleen hoe vaak een strategie in hun studie is genoemd. De geïnteresseerde lezer wordt verwezen naar de studie van De Jong en Ligterink. 